\title{
Green-house gas mitigation capacity of a small scale rural biogas plant calculations for Bangladesh through a general Life Cycle Assessment
}

\author{
Khondokar M Rahman ${ }^{1}$, Lynsey Melville ${ }^{1}$, David Fulford ${ }^{2}$ and S M Imamul Huq ${ }^{3}$, \\ Correspondence author's email: Khondokar.Rahman@bcu.ac.uk \\ ${ }^{1}$ Centre for Resilient Environments, Faculty of Computing, Engineering and Built \\ Environment, Birmingham City University, UK \\ ${ }^{2}$ Director, Kingdom Bioenergy Ltd, Reading, UK \\ ${ }^{3}$ Bangladesh-Australia Centre for Environmental Research, Department of Soil, Water and \\ Environment, University of Dhaka, Bangladesh
}

\begin{abstract}
Calculations towards determining the GHG mitigation capacity of a small scale biogas plant $\left(3.2 \mathrm{~m}^{3}\right.$ plant) using cow dung in Bangladesh are presented. A general life cycle assessment (LCA) was used, evaluating key parameters (biogas, methane, construction materials and feedstock demands) to determine the net environmental impact. The global warming potential (GWP) saving through the use of biogas as a cooking fuel is reduced from $0.40 \mathrm{~kg} \mathrm{CO}_{2}$ equivalent to $0.064 \mathrm{~kg} \mathrm{CO}_{2}$ equivalent per $\mathrm{kg}$ of dung. Biomethane used for cooking can contributes towards mitigation of global warming. Prior to utilization the GWP of methane (from $3.2 \mathrm{~m}^{3}$ biogas plant) the GWP is 13 tonnes of carbon dioxide equivalent. This reduced to 2 tonnes as a results of complete combustion of methane. The GWP saving of a bioenergy plant across a 20 year life cycle is 217 tonnes of carbon dioxide equivalent which is 11 tonnes per year. The GWP of the resultant digestate is zero and from construction materials is less than $1 \%$ of total GWP. When the biogas is used as a fuel for cooking the GWP will reduce by $83 \%$ compare to the traditional wood biomass cooking system. The total 80MJ of energy which can be produced from a $3.2 \mathrm{~m}^{3}$ AD plant would replace 1.9 tonnes of fuel wood or 632 $\mathrm{kg}$ of kerosene currently used annually in Bangladesh. The digestate can also be used as a nutrient rich fertilizer substituting more costly inorganic fertilizers, with no GWP impact.
\end{abstract}

Keywords: Anaerobic Digestion, Life Cycle Assessment, Global Warming Potential, Methane, Biogas, SimaPro. 


\section{Introduction}

Anaerobic digestion (AD) is the breakdown of organic material by micro-organisms in the absence of oxygen, which produces biogas, a methane-rich gas that can be used as a fuel, and digestate, a source of nutrients that can be used as a fertilizer. A common feed material for a rural biogas plant is cattle dung in many developing countries, although it can be co-digested with other materials, such as food-wastes, which gives improved ultimate biogas and methane yields compared to separate digestion (Adelard et al., 2015). The majority of biogas plants built in Bangladesh are for use by small farmers who feed them with dung from small number of cattle (3-4). According to van Ness and Island, 2005 the technical potential biogas in Bangladesh is approximately million units on the basis of livestock count in households. Bajgain (2006), in a later survey for SNV (Netherlands Development Organisation) suggested that 3 million small sized biogas plants are technically feasible in Bangladesh. This calculation was based on the number of livestock in household units in Bangladesh. In practice, extension programmes have been able to build only 50,000 small biogas plants for such farmers by 2011 (SNV, 2011). This number indicate that the existing number of AD plant is far behind from its actual potential (only $1.66 \%$ of the total potential) of Bangladesh. A number of factors could be identified which constrains the biogas program in Bangladesh. These includes: technical (product, process and training), social, economic, political (lack of commitment), promotional (lack of awareness), institutional and programmatic (lack of monitoring) (van Ness et. al., 2005). Biogas improves the environment through the reduction of indoor air pollution, carbon emission, deforestation and climate change. It's advantage will disappear if even a small percentage of the biogas leaks from the facility into the air before combustion. A good monitoring of the above factors would help to overcome the constraints of this programme. The best household energy technology from a global warming perspective, therefore, would still be biogas (Smith et. al., 2002). 
$\mathrm{AD}$ cattle dung is used in these plants to produce energy in remote rural areas, such as on small farms. Biogas, the primary product of anaerobic digestion is used in Bangladesh, as well as in many other developing countries as a fuel for domestic purposes. It replaces the use of traditional fuels mainly fire wood for cooking and kerosene for lighting (Gautam et al., 2009). Fire wood and kerosene are not only inefficient fuel sources but also cause environmental and health risks including an increase in the global warming potential (GWP). One benefit of AD is to mitigate GHG (Green House Gas) emissions from such sources. Other benefits from using biogas plants include a reduction in smoke from wood fires and a reduction in house fires caused by the spillage of kerosene. A life cycle assessment (LCA) was conducted to determine the reduction of GWP for a specific type of AD plant built in Bangladesh during its life using the software package SimaPro. Using SimaPro meant not only that the LCA analysis followed a standard method, but also meant that more subtle impacts, including some benefits could not be included.

\section{Use of LCA in AD}

LCA is a tool that can be used to compare the environmental impacts of different products throughout their entire life cycle (European Commission, 2010). The result of a LCA is a quantified environmental impact through an official and standardized "Impact Category". Due to a lack of robust and reliable data there are very few LCA studies on small scale production of biogas in developing countries. Although there are studies examining LCA for rural biogas, these do not always follow the methodology of a standard LCA procedure (ISO, 2006). The LCA methodology has been more widely used for other bioenergy applications (pyrolysis/gasification), rather than biogas production alone (Nguyen \& Gheewala, 2008). The most frequently used impact categories are: GWP, Acidification, Eutrophication, Ozone Layer Depletion and Human Toxicity (Baldo et al., 2008). A review conducted by Hijazi et. 
al. (2016) on the LCA of AD systems explored the LCA studies of 15 biogas systems from around Europe. These systems were at a much larger (plant size) than those used in Bangladesh. Biogas scenarios in all the studies provided results suggesting lower GHG intensities than their reference systems (of conventional manure management).

Despite the number of small-scale biogas digesters that have been deployed in developing countries (45 million in China, 4 million in India and 250,000 million in Nepal - Fulford, 2015), very few studies have focused on this type of biomass energy system. In East Asia the solid matter in the slurry is mainly pig dung, which has a low total solids content. When it is fed into the digester, it is further diluted by urine and washing water. Transportation of the liquid effluent digestate for use as a fertilizer in the fields is difficult (Thien Thu et al., 2012, Vu et al., 2015). This means that the use of the digestate containing fibre and nutrients is not considered in this work, as it is often discharged as a pollutant into the environment.

Another weakness is that biogas may leak from the system, which is a problem because it contains $\mathrm{CH}_{4}$ which is a potent greenhouse gas (Smith et. al., 2002). As methane has a global warming potential 25 times greater than that of carbon dioxide, this can compromise the environmental advantages of digesters (Bruun et al., 2014). Biogas digesters are sometimes poorly managed and there is a lack of proper quality control in the distribution systems for biogas in some places. There is limited information regarding methane leaking from smallscale biogas digesters in developing countries, but one report indicates that emissions may be as high as $40 \%$ of the gas generated. (Bruun et al., 2014). Studies which did focus on wider environmental impacts suggested that emissions from the AD process can vary significantly depending on feedstock utilisation and end-use of the biogas (Berglund, M. \& Borjesson, P., 2006).

Therefore the key challenges of biogas systems utilised in developing countries are: system design, poor operational management and utilisation of digestate. The GWP of construction 
materials is minimal and the main impact of GWP come from the secondary product (biogas) of anaerobic digestion.

Poor system design= leaking biogas $=$ impact of GWP

The proper knowledge of anaerobic digestion product and process and the maintenance could help to overcome the challenges. Therefore the GWP determination of a biogas system could be an indicator of the system design.

Several biogas programmes have applied to CDM (Clean Development Mechanism) for carbon offset finance (ter Heegde, 2008) such as Biogas Support Programme (BSP) in Nepal (CDM - Executive Board 2013). While the CDM scheme is out of date, it did inspire the development of methodologies (CDM Executive Board 2010) that are still in use by the voluntary carbon offset schemes. One such scheme is Gold Standard set up by WWF (World Wide Fund for Nature) and other international NGOs which is supporting projects run by SKG Sangha in South India (Gold Standard 2014). These methodologies provide a rigorous test to determine the reduction of GWP by using small scale biogas plants. Since such schemes are carefully evaluated before carbon offset money is paid to organisation, it ensures that these organisations manage and maintain all the systems that they install.

\section{A general LCA}

There are numerous tools for the assessment of environmental impacts of projects or processes including the CDM methodologies, but a commonly applied academic tool is lifecycle assessment (LCA). Some key challenges could be identified through the technoeconomic and socio-cultural assessment. Techno-economic and LCA together can provide economic viability and environmental sustainability criteria, supporting decision-making at different levels (e.g., policy maker) (Tao \& Han, 2015). It therefore can help to introduce better policy, change behaviour, provide facts to improve design or operation, leverage 
finance based on carbon credit. An integrated sustainability assessment also help to identify and overcomes the key challenges. LCA can determine the greenhouse gas emissions associated with the installation, operation, and end-of-life disposal of a small farm-based plant in a straightforward way. Thus it differs from the other impact assessment tools (such as The UK TIMES model, Ecosystem and resource models). An LCA is important because it is focused on fuel consumption and waste and the biggest driver for change is not its construction or its logistics, it's the $\mathrm{CO}_{2} / \mathrm{CH}_{4}$ savings and emissions that occur as a result. Commonly, domestic digesters in countries such as Bangladesh are constructed from brick, sand and cement although some also use plastic. Life cycle analysis starts by defining scope, goal and a system boundary in order to assess the environmental impact arising from the contribution of the biogas plant structural materials and construction of the overall $\mathrm{AD}$ system (materials, construction). The requirements for conducting an LCA are standardised and the techniques to be used are defined by the International Organization for Standardization (ISO, 2006).

This study is based on a rural AD facility in Bangladesh and follows the ISO standards as far as practicably possible. Methods of internal farming, transport and construction very considerably across Bangladesh. This poses a challenge when adopting the ISO methodology which has been, written from a European perspective and doesn't significantly account for variability. Also, it has been found that where biogas LCA studies exist there is limited definition of the study system boundaries. The aim of this study was to determine the GHG mitigation capacity of a small scale biogas plant through a general life cycle analysis. First, the system boundaries and the inputs and outputs of the process were determined. It was important to calculate how the GWP from the production of biogas and biogas components differs from alternative uses of the waste biomass and the use of fossil derived fuels for the 
applications for which the biogas is used. The representative domestic scale biogas plant that was considered in this study has a total internal volume of around $3.2 \mathrm{~m}^{3}$ (Gofran, 2009).

\section{Methodology}

A general LCA methodology was used to evaluate the life cycle impacts of an anaerobic digestion plant. The Publicity Available Specification (PAS) for the assessment of the GHG emissions associated with the life cycle of products and process and the UK PAS 2050 was followed (BSI, 2011). SimaPro is seen as one of the leading tools for analysing LCA and carbon footprints of projects and follows internationally accepted procedures, so version 7 and its Eco invent database was used as the software for analysis (SimaPro). It determines GHG emissions and their effect on the global warming potential (GWP). GWP is a SimaPro categorization impact which means gases such as carbon dioxide and methane cause an increase in the greenhouse effect in the atmosphere resulting in global warming. Global warming saving can be defined as the difference between the GWP of two routes (a chosen traditional use - baseline - and a well-managed $\mathrm{AD}$ system). This analysis was used to determine the GHG emissions associated with the installation, operation, and end-of-life disposal of a small farm-based AD plant. The goal and scope, functional units, data collection and inventory of material and energy flow is also be described in the LCA.

Quantitative data for biomass feedstock, AD product and process is not easily available for Bangladesh and the data that does exist is not reliable. Research conducted by Wilson et. al., (2009) on "Building recycling rates through the informal sector" found that quantitative data on this topic was scarce and not applicable to developing countries. The data for the study was obtained from organisations involved in biogas extension in Bangladesh, such as IDCOL (Infrastructure Development Company Limited) and Grameen Shakti. The data was checked with experts working with organisations involved in biogas programmes in Bangladesh, such 
as BCSIR (Bangladesh Council of Scientific and Industrial Research), BBDF (Bangladesh Biogas Development Foundation), DLS (Department of Livestock Service) and the Institute of Energy at Dhaka University.

Goal, Scope, Functional unit and System boundary

The goal of this study was to determine the GHG mitigation capacity of small-scale anaerobic digestion of cattle dung in Bangladesh through LCA. The objective was to identify the important factors that affected the environmental load of a biogas generation plant. The system boundary was counted from collection of raw materials. Construction materials for the digester, the feedstock used in the digester, the outputs from AD (biogas and digestate) are used to develop an entire life cycle analysis of the process defining a system boundary for this work. The boundaries did not include the energy required in the transport and spreading of the digestate as it was handled manually. The disposal of the materials in a biogas plant at the end of its life is also not considered. Unused plants are usually left in place, as much of the plant is underground.

LCA of the construction an AD plant

The LCA boundary of this research starts from the materials acquisition (e.g. brick, cement production) needed to build the plant. The process map for evaluation of the GWP associated with the installation of the $\mathrm{AD}$ plant are: acquisition, production and transport of raw materials, and their use in the construction of the plant. In the system boundary the production and use of the entire AD plant is considered. However the GWP impact only includes the production of the construction materials (i.e. brick, cement, sand, iron, plastic) as the actual construction of an AD plant is done by manual labour, so no embodied energy is considered. Although energy (in the form of food) is required for manual labour, it is not deemed to come from fossil sources. 
Acquisition of raw materials (Raw material for AD building material)

The lifetime energy requirements of the $\mathrm{AD}$ construction materials are considered in this study. This encompasses the raw material acquisition and their use in the AD plant. The major raw materials utilised in the construction of the digester are clay soil for bricks, iron for rods, sand, cement and PVC plastic materials. The raw materials used in the manufacture of cement are limestone, clay and iron ore. Finished cement is produced by finely grinding around together around $95 \%$ cement clinker with 5\% gypsum. Around $80-90 \%$ of raw material for the kiln feed is limestone (British Geological Survey, 2005).

In Bangladesh brick is prepared from clay soil and fired in a brick kiln where biomass wood and imported coal are used as the energy source. Sand comes from natural sources (e. g., bank of the river, sea shore). The farmer collects the construction materials to build an anaerobic digester from the local market. Generally, materials are transferred by hand into small vehicles (man powered rickshaws) for transportation to the site (Rahman, 2012). In a few cases when moving bulk loads of bricks and other building materials, larger motor vehicles are used for transportation. The lifetime of $\mathrm{AD}$ plants are considered to be 20 years (Gofran, 2009) in this analysis.

\section{Data inventory}

A typical LCA comprises of four important steps: goal and scope, inventory, impact assessment and interpretation (Joep \& Meijer, 2011). It includes materials and energy inventory for the AD building materials. 

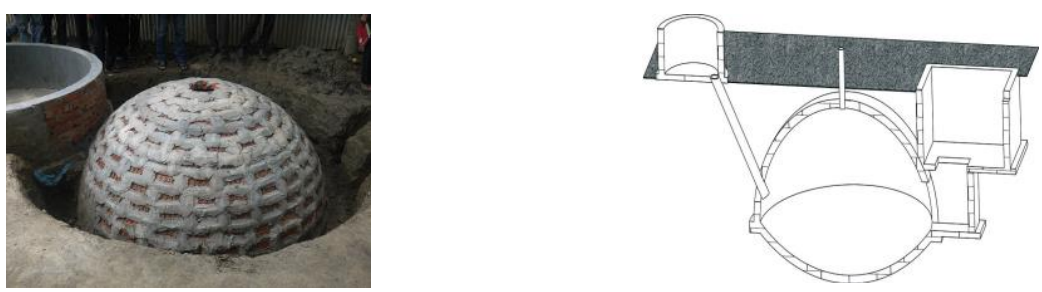

Figure 1. Diagram of Chinese fixed dome biogas plant model used in Bangladesh (left) (Fulford, 2015), Bangladeshi Brick-cement fixed dome (right)

This LCA has been conducted for a fixed dome AD plant with an internal volume of $3.2 \mathrm{~m}^{3}$ made from bricks and cement. This is the most popular AD plant in the country (Afful et al, 2012). There are 40,000 domestic AD plants presently installed in the country and $50 \%$ of them are have sizes between 3.0 and $3.2 \mathrm{~m}^{3}$ (Gofran, 2009).

Materials inventory for $\mathrm{AD}$ building materials

The data inventory of the materials used to construct a $3.2 \mathrm{~m}^{3} \mathrm{AD}$ plant (Figure 1) was provided from Grameen Shakti and IDCOL (IDCOL, 2008). All the materials were calculated in kilogram $(\mathrm{kg})$ from the construction manual used by biogas plant extension groups including IDCOL, Grameen Shakti and Advance Engineering Bangladesh (Table 1). 
Table 1. Inventory of materials for $3.2 \mathrm{~m}^{3}$ AD plant (IDCOL, 2008, translated by author)

\begin{tabular}{lccc}
\hline Materials & Number/amount & Each weight kg & Weight in kg \\
\hline Bricks $(25 \times 12.5 \times 7.5 \mathrm{~cm})$ & 1747 number & 3.5 & 6,115 \\
Sand (Fine-medium) $1.2-1.5 \mathrm{~mm}$ & $2.5 \mathrm{~m}^{3}$ & & 4,005 \\
Khoa (Brick particle) $1.9 \mathrm{~cm}$ & $0.65 \mathrm{~m}^{3}(277)$ & 971 \\
Cement (50 kg bag) & 21 bags & 50 & 1050 \\
Rod (10mm) & $26 \mathrm{~kg}$ & 26 \\
Paint (Acrylic Emulsion paint) & 2 litre & 1 \\
Polythene & 3 meter & 0.5 \\
Inlet PVC pipe $(10 \mathrm{~cm})$ & 6 meter & 2 \\
GI Ware \# 8 & $2 \mathrm{~kg}$ & 1 \\
\hline
\end{tabular}

Energy inventory for AD building materials

Considering the rural and small scale context of this research it assumed that there was no requirement for an associated transportation inventory. Generally, the farmers or rural stakeholders collect bricks; cement and rods from their local market and use the local nonfuel driven transport system or they carry the materials manually. The cost of transportation from the cement manufacturer to the market is allocated to the cement manufacturer, not to the user, as part of a business-to-business, B2B, process (PAS 2050, 2011, Rahman, 2012). This avoids double-counting.

Impact assessment of major building materials

The acquisition and production of the material is the embodied energy of the material from the process map. There was no data available for the acquisition of materials to produce brick or cement, so the embodied energy is calculated based on the energy needed to produce the 
materials used to construct the plant. The materials needed for a $3.2 \mathrm{~m}^{3}$ brick dome biogas digester are mainly clay bricks and cement. A few other materials like sand, rods, polythene, PVC pipes are also used to make up the digester. According to PAS 2050, if any individual product or process causes less than $1 \%$ of the total impact then it can be ignored (Rahman, 2012). So for material consideration, the life cycle inventory analysis and the energy association is defined for the production of clay bricks, sand, cement, plastic and cement. The defined inventory to build a $3.2 \mathrm{~m}^{3}$ biogas plant lists 2,024 bricks which weigh $7084 \mathrm{~kg}$ (including broken bricks), $1050 \mathrm{~kg}$ of cement, $4005 \mathrm{~kg}$ of sand, $26 \mathrm{~kg}$ of iron and $3.5 \mathrm{~kg}$ plastic (Table 1).

\section{Cement}

For cement production data, the information used was derived from the cement production of Bangladesh. According to Lafarge Cement Bangladesh (2007), to produce 1.2 million tonnes of cement per year in Bangladesh 1.5 million tonnes of limestone, 280,000 tonnes of clay and 140,000 tonnes of sandstone are needed. Using the input for the material requirements for the cement production for Bangladesh and the energy required to process the cement using natural gas, the GWP impact is $1.39 \mathrm{~kg} \mathrm{CO}$ equivalent per $\mathrm{kg}$ of cement (Haque, 2017), including transport to market.

\section{Bricks}

Bricks are made of clay soil and the clay is derived locally from fallow land, road side or river side. The bricks are manually made on site and fired in a brick kiln driven by wood biomass fuel or coal. Total production in Bangladesh is estimated at 15 billion bricks annually, and there is an extensive use of coal and wood in the industry, so the GHG emissions are estimated to be 8.75 million tonnes of $\mathrm{CO}_{2}$ equivalent annually (Ahmed, 2008). 
According to this $\mathrm{CO}_{2}$ emission per brick is $0.58 \mathrm{~kg}$. The weight of an average brick is $3.5 \mathrm{~kg}$, so the $\mathrm{CO}_{2}$ emission is $0.17 \mathrm{~kg}$ per $\mathrm{kg}$ of brick. According to an estimation conducted by Huque (2017), the carbon footprint is $0.18 \mathrm{~kg} \mathrm{CO}_{2}$ equivalent per $\mathrm{kg}$ of bricks.

Plastic, Sand and Iron

The generally accepted Carbon footprint of plastic is $3.8 \mathrm{~kg} \mathrm{CO}_{2}$ equivalent per $\mathrm{kg}$ (EPA's Waste Reduction Model). Therefore for $3.5 \mathrm{~kg}$ of plastic the carbon footprint is $13.36 \mathrm{~kg} \mathrm{CO}$ equivalent. Sand is a natural resource and hence no embedded energy needs to be considered (Huque, 2015). There is a figure for the GWP per kilogram sand $0.01 \mathrm{~kg} \mathrm{CO}_{2}$ equivalent (City of Winnipeg, 2012), assuming transport by trucks. The GWP of iron rod is $1.91 \mathrm{~kg} \mathrm{CO}_{2}$ equivalent/kg (City of Winnipeg, 2012). There is no data available for Bangladesh, so the Canadian data was used, which is likely to have higher values than that for Bangladesh.

A sensitivity analysis of the effects of variations in the values of this parameters on GWP was not done, but could have been helpful. A sensitivity analysis evaluates the influence of the most important assumptions have on the results (Goedkoop et. al., 2016).

\section{Results: LCA of a typical AD process and product}

Three key elements were considered when assessing the overall sustainability of these domestic AD systems. Firstly the GWP impact parameter associated with the installation and operation, then the methods used to quantify the GHG emissions avoided as a result of their use, and finally the benefits from energy production and use.

GWP derived from an AD plant

The AD raw material to disposal process map (Raw material - Production - Distribution Usage - Disposal) illustrates all of the non-contributing phases with the exception of the 
production of materials. These are the phases which have been considered as causing zero or negligible (in terms of LCA) emissions. The production of materials was considered for environmental impact calculations for the purposes of this investigation.

It is found that the GWP from materials that are used to construct the plant is $2,838 \mathrm{~kg}$ $\mathrm{CO}_{2}$ equivalent (Table 2). Since these plants are operated in a sub-tropical region with relatively high ambient temperatures, there is no need for them to be heated to maintain the optimum temperatures for $\mathrm{AD}$ reactions. This means that the impact of this aspect of running these plants on GWP can be ignored, which is not true for AD plants in colder climates, such as in Europe.

Table 2. Inventory of materials for $3.2 \mathrm{~m}^{3} \mathrm{AD}$ plant

\begin{tabular}{lllll}
\hline Materials & Amount (in kg) & GWP/kg & GWP (kg CO eq.) & Remarks \\
\hline Bricks, & & & & \\
including & & 0.18 & 1275 & Natural resource \\
broken ones & 7084 & 1.39 & 1460 & \\
Cement & 1050 & 0.01 & 40 & \\
Sand & 4005 & 1.91 & 50 & \\
Iron rod & 26 & 3.8 & 13 & \\
Plastic & 3.5 & & 2,838 & \\
\hline Total & & & & \\
\hline
\end{tabular}

GWP derived from an AD process

The GWP of the, operation of the AD process is considered here. The AD feedstock manure is mixed with water to form slurry and fed into the anaerobic digester. The biochemical conversion process produces biogas as the primary and a digestate as a secondary output. 
There are no further residues or emissions. The biogas is used as a fuel, mainly for cooking and the digestate is returned to the land as a nutrient rich fertiliser. In order to promote bacterial degradation within the digester a 1:1 mixture of manure and water is used.

For the purpose of this LCA study, and based on typical scale of $3.2 \mathrm{~m}^{3}$ an initial input of $4,000 \mathrm{~kg}$ of cattle dung is required to start the plant. After that, a daily input $87 \mathrm{~kg}$ of dung is used. According to Grameen Shakti the biogas yield is $0.037 \mathrm{~m}^{3} / \mathrm{kg}$ for manure and the biogas composition is principally $\mathrm{CH}_{4}(60 \%)$ and $\mathrm{CO}_{2}$ (39.90\%). The conversion to weight of gas per $\mathrm{kg}$ of cow dung for input to SimaPro is shown in Table 3 (Rahman, 2012). According to this, the total gas produced from the daily input ( $87 \mathrm{~kg}$ of dung) is $3.057 \mathrm{~kg}$ by weight where the methane content is $1.454 \mathrm{~kg}$, the rest being mainly carbon dioxide.

Table 3. Corresponding conversion to weight of biogas per $\mathrm{kg}$ of cow dung.

\begin{tabular}{llll}
\hline Biogas & Density $\left(\mathrm{kg} / \mathrm{m}^{3}\right)$ & Wt gas $/ \mathrm{kg}$ dung $(\mathrm{g})$ & Wt gas in $87 \mathrm{~kg}$ dung $(\mathrm{kg})$ \\
\hline $\mathrm{CH}_{4}$ & 0.657 & 16.714 & 1.454 \\
$\mathrm{CO}_{2}$ & 1.811 & 18.092 & 1.574 \\
$\mathrm{CO}$ & 1.145 & 0.000 & 0.000 \\
$\mathrm{O}_{2}$ & 1.309 & 0.145 & 0.013 \\
$\mathrm{H}_{2} \mathrm{~S}$ & 1.410 & 0.052 & 0.005 \\
$\mathrm{H}_{2}$ & 0.082 & 0.079 & 0.007 \\
$\mathrm{~N}_{2}$ & 1.146 & 0.051 & 0.004 \\
\hline TOTAL & & 35.133 & 3.057 \\
\hline
\end{tabular}

GWP Impact of Biogas (from cow dung)

The environmental impact was determined for the gases (Table 4). On the basis of the SimaPro analysis, it was found that $\mathrm{O}_{2}, \mathrm{~N}_{2}$ and $\mathrm{H}_{2}$ have no GWP impacts but $\mathrm{CH}_{4}$ and $\mathrm{CO}_{2}$ 
are greenhouse gases with global warming potential (GWP) of 23 and $1 \mathrm{~kg} \mathrm{CO}$ equivalent respectively. Methane also has a photochemical oxidation impact indicated by $\mathrm{kg}_{2} \mathrm{C}_{4}$ equivalent (Table 4). $\mathrm{H}_{2} \mathrm{~S}$ does not have any global warming effect but has human toxicity effect of $0.22 \mathrm{~kg} 1,4-\mathrm{DB}$ equivalent.

Table 4. GWP and some other environmental impacts per kg gas (Using SimaPro)

\begin{tabular}{lllll}
\hline Impact category & Unit & $\mathrm{CH}_{4}$ & $\mathrm{CO}_{2}$ & $\mathrm{H}_{2} \mathrm{~S}$ \\
\hline Global Warming (GWP 100) & $\mathrm{kg} \mathrm{CO}$ equivalent & 23 & 1 & 0 \\
Human toxicity & $\mathrm{kg} \mathrm{1,4-DB}$ equivalent & 0 & 0 & 0.22 \\
Fresh water aquatic ecotox. & $\mathrm{kg} \mathrm{1,4-DB}$ equivalent & 0 & 0 & 0 \\
Photochemical oxidation & $\mathrm{kg} \mathrm{C}_{2} \mathrm{H}_{4}$ equivalent & 0.006 & 0 & 0 \\
\hline DB = dichlorobenzene & & & &
\end{tabular}

Note: Table 4 lists the outputs from SimaPro, even though some of these are less relevant in this particular analysis.

Given that the manure is considered a waste product, and water addition for manual mixing is taken from the nearby pond or tube well, there is no embodied energy attributed to this material. Manure is a by-product from a process (looking after cattle) that has other primary products (milk, energy for agriculture and food). For the digestion itself, the reaction proceeds according to a mesophilic regime without any additional heating. The GWP from supporting the reaction process and the reaction itself is also therefore zero.

The GWP due to the initial charge is 1.61 tonnes $\mathrm{CO}_{2}$ equivalent. The daily charge is the amount of feedstock added every day to maintain the operation of the digester. For a $3.2 \mathrm{~m}^{3}$ plant a daily biogas production yielding a GWP of $35 \mathrm{~kg} \mathrm{CO}_{2}$ equivalent. Assuming a lifetime of an $\mathrm{AD}$ plant is 20 years and for a lifetime yield production required of lifetime dung (= daily x 365 days/year x 20 years $=635100)$ is $635100 \mathrm{~kg}$. This gives a GWP of 256 
tonnes $\mathrm{CO}_{2}$ equivalent. The total impact is the sum of contribution from the initial charge and lifetime charge. The GWP impact due to the biogas for a $3.2 \mathrm{~m}^{3}$ plant operating for 20 years is 258 tonne $\mathrm{CO}_{2}$ equivalent (including impact of initial charge 1.61 tonnes).

Table 5. Life time (20 year) impact of a $3.2 \mathrm{~m}^{3}$ dung based biogas plant (before the methane is burnt)

\begin{tabular}{|c|c|c|c|c|c|}
\hline Impact category & Unit & Initial charge & Daily charge & Lifetime charge & Total \\
\hline Weight dung & $1 \mathrm{~kg}$ & 4 ton & $87 \mathrm{~kg}$ & 635 ton & 639 ton \\
\hline $\mathrm{GWP} \mathrm{CO}_{2}$ eq. & $.40 \mathrm{~kg}$ & 1.6 ton & $35 \mathrm{~kg}$ & 256 ton & 258 ton \\
\hline
\end{tabular}

The methane rich biogas is used as fuel for cooking thus converting methane to $\mathrm{CO}_{2}$. Assuming $100 \%$ conversion, each molecule of methane is converted to a molecule of $\mathrm{CO}_{2}$. For every molecule of methane burned, a molecule of $\mathrm{CO}_{2}$ is produced $\left(\mathrm{CH}_{4}+2 \mathrm{O}_{2} \rightarrow \mathrm{CO}_{2}+\right.$ $2 \mathrm{H}_{2} \mathrm{O}$ ). The GWP per unit $\mathrm{kg}$ of manure is $0.40 \mathrm{~kg} \mathrm{CO}$ equivalent. For a daily amount of $1.27 \mathrm{~kg}$ methane produced, $3.99 \mathrm{~kg}$ of $\mathrm{CO}_{2}$ is produced. It shows the global warming saving through the use of biogas in combustion where the GWP attributed to biogas used drops from $0.40 \mathrm{~kg} \mathrm{CO} 2$ equivalent/ $\mathrm{kg}$ dung to $0.064 \mathrm{~kg} \mathrm{CO}_{2}$ equivalent $/ \mathrm{kg}$ dung (Table 6). 
Table 6. GWP per kg of dung before and after burning of methane.

\begin{tabular}{lllll}
\hline & Biogas & GWP & Wt gas/kg dung & GWP/kg dung \\
& Gas & kgCO ${ }_{2}$ eq/kg gas & grams & $\mathrm{kgCO}_{2}$ eq \\
\hline Before & $\mathrm{CH}_{4}$ & 23 & 16.71 & 0.38 \\
Combustion & $\mathrm{CO}_{2}$ & 1 & 18.09 & 0.02 \\
& $\mathrm{CH}_{4}$ & 23 & 0 & 0 \\
After & & & $18.09+25.95$ & \\
Combustion & $\mathrm{CO}_{2}$ & 1 & $(16.71 \times 2.75=45.95)$ & .064 \\
\hline
\end{tabular}

This indicates that the life time (20 year) GWP impact of a $3.2 \mathrm{~m}^{3}$ biogas plant before combustion of methane is 258 tonnes $\mathrm{CO}_{2}$ equivalent but it is significantly reduced to 41 tonnes of $\mathrm{CO}_{2}$ equivalent following combustion of methane. Unluckily, very little information is available about methane losses from small-scale biogas digesters in developing countries. The fugitive emissions of methane from the digester leaks depends upon how these are maintained. A study in China concluded that fugitive methane emissions from leaks are negligible because the digesters that were used for the measurements were well maintained (Dhingra et. al., 2011). To date no international standard exists for the measurement of fugitive and diffuse methane emissions from anaerobic digestion facilities. There is a basic guideline on the investigation of diffuse sources where remote sensing methods are considered. However, fugitive emissions even from well-maintained biogas digesters in a developed country have been estimated to be as high as $3.1 \%$ of methane production under normal operation (Flesch et. al., 2011).

In practical terms, the traditional disposal of the dung produces emissions of methane. The methane is used for cooking and displaces inefficient combustion of wood fuel, which is often not collected in a sustainable way (Sepp, 2014). In Bangladesh, firewood is obtained by 
people from wherever they can find it, although some is sourced from their own land. The low efficiency of a basic stove means much of the energy is wasted. These savings are approximated by assuming they are equivalent to a reduction of 217 tonnes of $\mathrm{CO}_{2}$ equivalent GWP (Table 7), as a result of burning the methane for use in cooking. This represents an $84 \%$ reduction in GWP by using AD to capture the methane for use in cooking.

The LCA used a simplification of not taking into account the burning of firewood. A full analysis of the benefits of biogas technology, based on replacing firewood and reducing the health issues related to the burning of firewood, has been covered in many other reports. Including these issues in the LCA would make the calculations too complex. Therefore a further point by point baseline calculation of an entire system has not been considered. If all the impacts are considered it could provide even more $\mathrm{CO} 2$ credits including social, health and economic benefits.

Table 7. Total GWP saving (t-CO $\mathrm{CO}_{2}$ eq.) through methane combustion $\left(\mathrm{CH}_{4}+2 \mathrm{O}_{2}=\mathrm{CO}_{2}+\right.$ $\left.2 \mathrm{H}_{2} \mathrm{O}\right)$.

\begin{tabular}{lllll}
\hline Impact category & Initial charge & Daily charge & Lifetime charge & Total (t) \\
\hline Weight of dung & $4000 \mathrm{~kg}$ & $87 \mathrm{~kg}$ & 635 tonne & 639 \\
GWP before burning & 1610 & $35 \mathrm{~kg}$ & 256 & 258 \\
GWP after burning & 256 & $5.57 \mathrm{~kg}$ & 40.74 & 41 \\
\hline Reduction in GWP from $\mathrm{CH}_{4}$ combustion & & 217 \\
\hline
\end{tabular}

Impact of Digestate

Digestate is a rich blend of fibre, water and is nutrient rich. The rich nutrients and characteristics of digestate make it a useful soil conditioner. The impact of returning this 
digestate fraction to land was evaluated, particularly the impact on soil and water quality. The results from using the software model suggest there is no contribution to GWP from the digestate (from SimaPro Table 8), but this may be related to assumptions made in the design of the model. In comparison with traditional manure storage, anaerobic digestion of animal manure not only avoids methane $\left(\mathrm{CH}_{4}\right)$ and nitrous oxide $\left(\mathrm{N}_{2} \mathrm{O}\right)$ leakage but also adds to the substitution of artificial mineral fertilizer (Hijazi et. al., 2016)).

An LCA was quantitatively performed for a product using SimaPro (version 7). The quantitative data for the product and process was considered (Zbicinski et. al., 2006). Reliable quantitative data for different plant nutrients of synthetic fertilizer and organic digestate (soil conditioner) are limited for many developing countries such as Bangladesh. Research was conducted by Wilson et. al., (2009) on "Building recycling rates through the informal sector" and found that quantitative data on this topic was scarce and unreliable in developing countries. An LCA must make simplifications and assumptions. Neglecting mineral fertilizer substitution is a declared assumption, which simplifies the calculations.

Table 8. Impact of $1 \mathrm{~kg}$ digestate in soil (derived from SimaPro)

\begin{tabular}{lllll}
\hline Impact category & Unit & $\mathrm{N}$ & $\mathrm{P}$ & $\mathrm{Zn}$ \\
\hline Eutrophication & $\mathrm{kg} \mathrm{PO}$ equivalent & 0.42 & 3.06 & 0 \\
Human toxicity & $\mathrm{kg}$ 1,4-DB equivalent & 0 & 0 & 63.7 \\
Fresh water aquatic ecotoxicity & $\mathrm{kg}$ 1,4-DB equivalent & 0 & 0 & 47.7 \\
Marine aquatic ecotoxicity & $\mathrm{kg}$ 1,4-DB equivalent & 0 & 0 & 7210 \\
Terrestrial ecotoxicity & $\mathrm{kg} 1,4-\mathrm{DB}$ equivalent & 0 & 0 & 24.6 \\
\hline DB = dichlorobenzene & & & &
\end{tabular}


Nitrous Oxide $\left(\mathrm{N}_{2} \mathrm{O}\right)$ has a GWP 265-298 times that of $\mathrm{CO}_{2}$ for a 100-year timescale and this is a big issue for European agriculture, but not necessarily for agriculture in Bangladesh. The amount of nitrogen in the soils used by farmers in Bangladesh is probably too low, so added nitrogen from biogas effluent may not have the same bad environmental effects. The nitrogen percent (by weight) of cow dung and poultry based digestate are 1.29 and 2.73 respectively (Islam, 2006) whereas synthetic (chemical) fertilizer (e. g., Urea - NH2-CONH2) contains $46 \%$ of nitrogen.

A more strict analysis would consider the GWP of the mineral fertilizer that the effluent slurry replaces. Mineral nitrogen is usually in the form of urea which is made from ammonia. Ammonia is made from natural gas and nitrogen from the air, using the Haber process, which is very energy intensive. Mineral phosphorus and potassium are usually mined as rocks and then crushed, which is also an energy intensive process. The fossil energy content of artificial fertilisers is often ignored in this context, as the value of the fertiliser content of digestate has not been well researched. (ter Heedge, 2008).

The energy required for $1 \mathrm{~kg}$ of inorganic nitrogen is $44.94 \mathrm{MJ}$, giving a GWP of $2.79 \mathrm{~kg}$ $\mathrm{CO}_{2}$ equivalent. The figures for phosphorous are $6.95 \mathrm{MJ}$ and $0.74 \mathrm{~kg} \mathrm{CO}_{2}$ equivalent and for potassium are $3.78 \mathrm{MJ}$ and $0.35 \mathrm{~kg} \mathrm{CO}_{2}$ equivalent (Jayasundara, 2014). These figures are from a Canadian report, but the artificial fertiliser supply industry is international and the figures are assumed to be similar (or more) for Bangladesh. The average content of plant nutrients in effluent slurry from a biogas plant is: nitrogen $1.6 \%$, phosphorous $1.55 \%$ and potassium 1\% (CMSN, 1996). Using these figures suggest that putting 1 tonne of AD effluent on crops saves 0.06 tonnes $\mathrm{CO}_{2}$ equivalent, if it replaces the equivalent inorganic fertilizer. This suggests that the SimaPro software should be updated to account for this. However, further research is needed to substantiate these figures, as they are not widely accepted in the published literature. 
The deterioration of rural environments and ecological system has become a worldwide concern and has been attributed to the excessive utilization of land and forest, excessive use of chemical fertilizers and pesticides and the careless discharge of livestock waste (Sasse, 1988). Research has shown that digestate from AD plants can be used successfully in enhancing crops cultivation. The concentration of nitrogen in digestate is greater than that from fresh dung, as carbon, hydrogen and oxygen are lost as biogas. $1 \mathrm{~kg}$ of digestate contains an extra $0.5 \mathrm{~kg}$ of nitrogen compared to $1 \mathrm{~kg}$ of fresh manure (Sasse, 1988). The use of digestate as an organic fertilizer not only reduces the dependency of chemical fertilizers but can also improve soil structure. This can solve problems of soil degradation in areas where earlier dung has been used as a burning fuel. Using less artificial fertilizer provides economic savings to the household ( $\mathrm{Li}$ et al., 2005). These aspects are not considered in the SimaPro software, which therefore underestimates the benefits of using AD. The saving, as estimated above, is that 1 tonne of digestate, used as fertiliser, replaces 0.06 tonnes $\mathrm{CO}_{2}$ equivalent from arterial fertiliser, but further research is required to substantiate this.

The type of households who purchase biogas plants are those who have been able to improve their lifestyles through improved household income. If such people are not able to install a biogas plant, they are likely to switch to the use of fossil fuels, such as kerosene or LPG for cooking. This concept of "suppressed demand" (ter Heedge, 2008) is not used in this study, but has been used in calculating the effect of biogas in reducing GWP in other studies. 


\section{Discussion of Results}

The results are summarised in the map (Figure 2) which can be called the Life Cycle Assessment of a domestic anaerobic digestion plant.

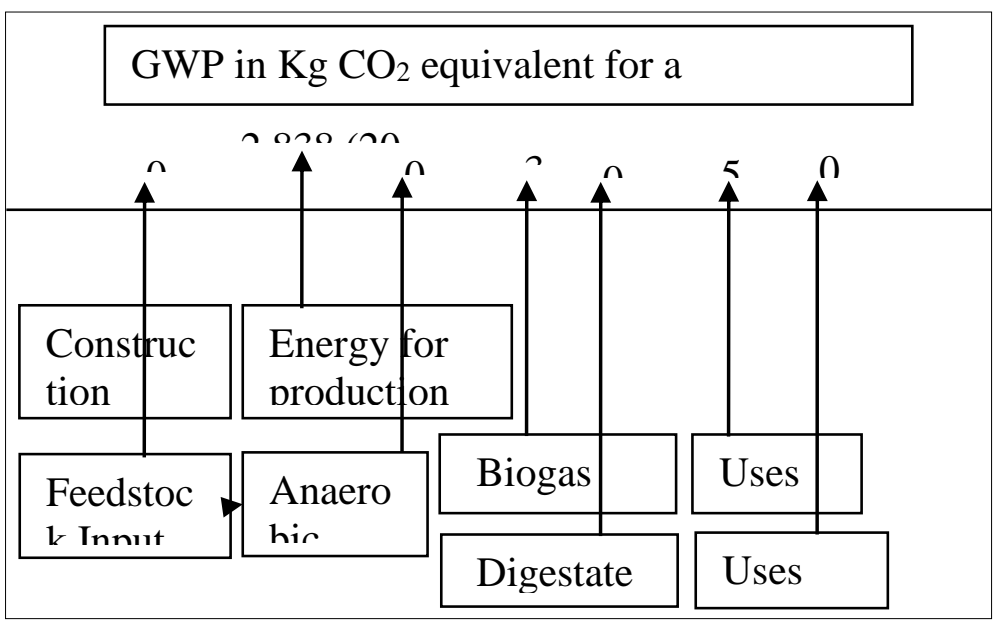

Figure 2. GWP of product and process of $\mathrm{AD}$

From the analysis above the GWP from bricks, sand, iron, plastic and cement used to build up a $3.2 \mathrm{~m}^{3}$ biogas plant was

$2,838 \mathrm{~kg} \mathrm{CO} 2$ equivalent. The daily accounting of the GWP is shown in the map. It is mostly from the biogas. For fuel the GWP is $35 \mathrm{~kg} \mathrm{CO}_{2}$ equivalent and after usage it is $5.6 \mathrm{~kg} \mathrm{CO}_{2}$ equivalents, an $84 \%$ reduction in GWP. The lifetime GWP on the basis of a ten year lifetime of a $3.2 \mathrm{~m}^{3}$ biogas plant is shown in below (Table 9).

Table 9. GWP (Tonnes $\mathrm{CO}_{2}$ equivalent) of a $3.2 \mathrm{~m}^{3}$ biogas plant of different parameters.

\begin{tabular}{lll}
\hline Parameters & $\mathrm{CH}_{4}$ before burning & $\mathrm{CH}_{4}$ after burning \\
\hline Biogas & 258 & 41 \\
Digestate & 0 & 0 \\
Structural materials & 2.84 & 2.84 \\
\hline
\end{tabular}




\begin{tabular}{|c|c|}
\hline 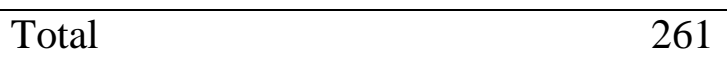 & 44 tonnes -20 years life time \\
\hline 20 year life time GWP saving & 217 tonnes $\mathrm{CO}_{2}$ eq. \\
\hline Yearly GWP saving & 11 tonnes $\mathrm{CO}_{2}$ eq. \\
\hline Emission reduction $\mathrm{CH}_{4}$ burning & $83 \%$ \\
\hline
\end{tabular}

On the basis of a year, the GWP of a $3.2 \mathrm{~m}^{3}$ biogas plant before and after methane burn is 13 and 2 tonnes of $\mathrm{CO}_{2}$ equivalent respectively. This is deriving principally from the production of the biogas. The GWP saving over 20 years is 217 tonnes of $\mathrm{CO}_{2}$ equivalent which is 11 tonnes per year. The contribution from digestate is taken as zero. When the biogas is used as a fuel then the GWP will reduce by $83 \%$. To determine the GWP of an AD plant, the information mainly needed is the daily volume of biogas produced per weight of feed and the composition of the biogas.

Energy attributes of AD plant

A key aspect required for this study is an estimation of the energy capacity of biogas as a fuel. The heat from the combustion of $1 \mathrm{~kg}$ of methane is 55.6 MJ. Based on calculations a $3.2 \mathrm{~m}^{3}$ biogas plant can produce $1.45 \mathrm{~kg}$ of methane per day. The heat energy of $1.45 \mathrm{~kg}$ methane is $(55.6 \times 1.45=80 \mathrm{MJ}) 80 \mathrm{MJ}$. This is based on a biogas produced from $87 \mathrm{~kg}$ of dung feed in a $3.2 \mathrm{~m}^{3}$ plant. The GWP is $5.57 \mathrm{~kg} \mathrm{CO}_{2}$ equivalent after combustion of the daily yield of biogas.

Replacing alternative traditional fuels with biogas

Combustion of $1 \mathrm{~kg}$ of wood produces only 15.5 MJ. A $3.2 \mathrm{~m}^{3}$ domestic sized biogas plant produces $80 \mathrm{MJ}$. This indicates that this biogas plant can save $5.2 \mathrm{~kg}$ of wood daily (Table 10). This means in the 20 year life time of a $3.2 \mathrm{~m}^{3}$ domestic biogas plant, the use of 
biogas will save more than 38 tonnes of biomass fuel. The following table summarises these points.

Table 10. Calculation shows efficiency of biogas over traditional biomass fuel.

\begin{tabular}{ll}
\hline Factors & Units \\
\hline Heat from combustion of methane & $55.6 \mathrm{MJ} / \mathrm{kg}$ \\
Daily methane production from $3.2 \mathrm{~m}^{3}$ plant & $1.45 \mathrm{~kg}$ \\
Heat from combustion of daily methane production & $80 \mathrm{MJ}$ \\
Heat combustion of wood & $15.5 \mathrm{MJ} / \mathrm{kg}$ \\
Daily methane production of a $3.2 \mathrm{~m}^{3}$ plant can save & $5.2 \mathrm{~kg}$ wood daily \\
A $3.2 \mathrm{~m}^{3}$ domestic biogas plant can save in its life time $(20$ year $)$ & 38 tonnes of wood \\
Boiling 1 litre of water needs & $0.31 \mathrm{MJ}$ heat \\
Methane produced daily in a $3.2 \mathrm{~m}^{3}$ plant can boil & $258 \mathrm{Litres}$ of water \\
\hline
\end{tabular}

Biogas is used mostly for cooking and lighting and replaces wood biomass. Biomass fuel stoves are a significant source of pollution in the form of products from incomplete combustion (PIC), i.e., much of this fuel carbon is diverted into non- $\mathrm{CO}_{2}$ airborne emissions such as $\mathrm{CO}, \mathrm{CH}_{4}, \mathrm{NMHC}$, and particles which can have deleterious impacts on health (Edward, 2002). The burning of sustainably harvested fuel wood (and other biomass) has often been assumed to be GHG neutral as $\mathrm{CO}_{2}$ which is released on combustion will be recycled and taken up by vegetation in the longer term. However, the low efficiency of combustion in open fires $(14 \%$, G. Ballard-Tremeer et al, 1996) suggests that much of the energy in the wood is wasted.

Firewood is widely used in developing countries. PIC of firewood causes indoor air pollution and increases the propensity to diseases such as pneumonia and other acute lower 
respiratory infections, and chronic obstructive pulmonary diseases (WHO, 2015). Of the commercial fuels, coal and kerosene are two of the most common fuels used for cooking. They are both fossil fuels, contributing to climate change and can be expensive to use (Gautam et al 2009; Li et al, 2005). If biogas is first produced from the dung then used the heating efficiency is about $60 \%$ (Mirza et al., 2008, Khandelwal, 2009). Thus, the use of biogas for cooking in well-designed gas stoves is highly desirable.

Replacing kerosene with biogas

Kerosene is a fossil fuel that is widely used in many developing countries for cooking and lighting. It is expensive, although it is often subsidised, and is usually imported. In areas where biogas plants have been installed, the use of kerosene has dropped considerably (Gautam et al 2009). Biogas can replace kerosene for lighting. Used 4 hours per day, a kerosene lamp emits $100 \mathrm{~kg}$ of $\mathrm{CO}_{2}$ annually and $100 \mathrm{~kg} \mathrm{CO}_{2}$ is produced from burning 28.9 kg kerosene (Atul Raturi, 2008). Comparing these research results it can prove that the GWP of kerosene and biogas are similar per energy. The caloric value of kerosene and methane is 46.2 and $55.6 \mathrm{MJ} / \mathrm{kg}$ respectively. The daily average kerosene requirement of a rural family in Bangladesh is $0.15 \mathrm{~kg}$ which is equivalent to $6.93 \mathrm{MJ}$. Based on this, biogas can replace $632 \mathrm{~kg}$ of kerosene annually from a $3.2 \mathrm{~m}^{3}$ biogas. To produce this amount of energy emits $0.52 \mathrm{~kg} \mathrm{CO}$ equivalent. The emissions for kerosene per MJis $0.075 \mathrm{~kg} \mathrm{CO}_{2}$ equivalent. According to this, to produce $80 \mathrm{MJ}$ of energy from a $3.2 \mathrm{~m}^{3}$ biogas plant emits $5.6 \mathrm{~kg} \mathrm{CO}_{2}$. It means for biogas, per $\mathrm{MJ}$ emission is $0.070 \mathrm{~kg} \mathrm{CO}$ equivalent. It means that replacing kerosene with biogas is quite logical in the aspect of GWP. Biogas is seen as much safer than using firewood and kerosene. Many children in rural areas suffer burns from falling into open wood fires, so biogas stoves reduce the danger of burns. Illnesses resulting from cooking and lighting fuel are estimated to cause the deaths of more women in many rural developing 
countries (e. g., Kenya, Bangladesh) than both malaria and tuberculosis (Bruce et. al., 2000). In addition, the use of kerosene lanterns frequently leads to accidents where houses burn down after a lamp falls down (Global Alliance for Clean Cookstoves, 2011). Kerosene lamps can be knocked over and cause house fires, as the burning liquid kerosene spreads across a floor; this cannot happen with fixed biogas lamps.

\section{Conclusion}

It was found that the use of biogas produced by anaerobic digestion offers benefits in terms of a reduction in GWP when compared with traditional practices (cooking by wood fuel and lighting by kerosene). The other product of anaerobic digestion, which is the digestate, was not shown in this analysis to contribute to GWP, but this may be due to the limitation of reliable quantitative data that was available for use in the software SimaPro. The outcome of the LCA is heavily dependent on some of the assumptions. An LCA requires assumptions and simplifications, which need to be declared. The analysis is valid, in the light of these assumptions and simplifications. It is possible that a different set of assumptions would produce different results, but that then becomes a different analysis. Again, there is no single answer as everything depends on the assumptions used.

When considering the 20 year life cycle assessment of these digesters, it found that the carbon attributed to the construction of the digester and its operation resulted in a GWP of 261 tonnes of $\mathrm{CO}_{2}$ equivalent. However, when the product of digestion, methane, is used as a fuel and converted to $\mathrm{CO}_{2}$ and water the GWP drops significantly to 44 tonnes of $\mathrm{CO}_{2}$ equivalent. This represents an $83 \%$ reduction in GWP for the process. The analysis did not suggest a value for the GWP associated with the digestate and so the major source of GWP considered in this study was the biogas. The GWP per year of a $3.2 \mathrm{~m}^{3}$ biogas plant before and after methane burn is 13 and 2 tonnes of $\mathrm{CO}_{2}$ equivalent respectively. This are deriving 
mainly from the production of the biogas. The GWP saving of a plant of its life time 20 years is 217 tonnes of $\mathrm{CO}_{2}$ equivalent which is 11 tonnes per year. The GWP from structural material is less than $1 \%$ of total. The results of this work can be used to estimate the GWP of an AD system based on feedstock and size variables. The information is useful for decision making in terms of the kind of $\mathrm{AD}$ systems that should be built within a local farm, a community or a commercial basis.

The finding that the GWP of the construction is only $1 \%$ of the total but this is a very useful one. Some people may claim that a masonry plant has a high environmental impact, as it uses cement in the construction. This paper can be used to refute that claim. This type of research is a step by step process. There are very few LCAs of the masonry dome design of biogas plant, as used in Bangladesh. This paper is a report of one of the first attempts at this analysis and a further analyses could help to produce a better (more satisfying) papers in future.

\section{Declaration of conflicting interests}

The authors declare that there is no conflict of interest.

\section{Funding}

This research received no specific grant from any funding agency in the public, commercial or not-for-profit sectors.

\section{Reference}

Adelard L., T G Poulsen and V Rakotoniaina, (2015). Biogas and methane yield in response to co- and separate digestion of biomass wastes, Waste Management \& Research 2015, Vol. 33(1) $55-62$ 
Afful, K., Devkota, G.P. and Fulford, D.J. (2012) Evaluation of Capacity Building in Nepal and Asia Biogas Programme, Kingdom Bioenergy Ltd with Practical Action for SNV

Ahmed S. F, Sameer A and S. Vaideeswaran, (2008). Urban Air Quality, Climate Change, and Development: An Integrated Approach to "Greening" the Brick Industry in Dhaka, Bangladesh. Bangladesh Brick Manufacturers Association.

Atul Raturi, (2008). CDM and the Pacific Island Countries Opportunities and challenges USP, Presented at JICA-CDM TV seminar, Suva.

Bajgain (2006). Implementation Plan: National Domestic Biogas and Manure Programme in Bangladesh; SNV

Ballard-Tremeer, G., Jawurek H.H. (1996) Comparison of five rural, wood-burning cooking devices: Efficiencies and emissions, Biomass and Bioenergy, Vol. 11, Issue 5, pp 419-430

Baldo , GL , Mariano , M. , Rossi , S. , (2008). Analysis of the life cycle LCA manuals sustainable design Environmental Issues.

Barua D C, (2007). Biogas plant Construction, Use, Maintenance and Grameen Shakti Organic Fertilizer Production \& Utilization Guide.

Berglund, M. \& Borjesson, P., (2006). Assessment of energy performance in the life cycle of biogas production, Biomass and Bioenergy, vol. 30, no. 3, pp. 254-266.

British Geological Survey, (2005). Mineral profile: Cement raw materials, Natural Environment Research Council, Office of the Deputy Prime Minister.

Bruun, S., L. S. Jensen, V. T. Khanh Vu, and S. G. Sommer., (2014). Small-scale household biogas digesters: An option for global warming mitigation or a potential climate bomb? Renewable and Sustainable Energy Review. 33:736-41.

Bruce, N., Pérez-Padilla, R. and Albalak, R. (2000). Indoor air pollution in developing countries: A major environmental and public health challenge. Bulletin of the World Health Organization, 78(9): 1078-1092. 
BSI, (2011). How to carbon footprint your products, identify hotspots and reduce emissions in your supply chain The Guide to PAS 2050:2011

CDM Executive Board (2010). "Indicative simplified baseline and monitoring methodologies for selected small-scale CDM project activity categories- Methane recovery through controlled anaerobic digestion" UNFCCC/CCNUCC III.AO./Version 01 Sectoral Scope: 13 EB 58

CDM - Executive Board (2013). Biogas Support Program - Nepal Activity-4 PROJECT DESIGN DOCUMENT (PDD) (F-CDM-SSC-PDD) Version 04.1

City of Winnipeg, (2012). Emission factors in kg CO2-equivalent per unit; Documents for Bid Opportunity 682-2012_Appendix_H-WSTP_South_End_Plant_Process_Selection_ Report Appendix 7

CMSN, (1996). Biogas Technology: a Training Manual for Extension FAO, Support for Development of National Biogas Programme (FAO/TCP/NEP/4451-T)

Dhingra R, Christensen ER, Liu Y, Zhong B, WuCF, Yost MG, (2011). Greenhouse gas emission reductions from domestic anaerobic digesters linked with sustainable sanitation in rural China. Environmental Science and Technology; 45:2345-52.

Directive 2009/28/EC of the European Parliament and of the Council, (2009). Promotion of the use of energy from renewable sources

Edwards Rufus and Kirk R. Smith UC Berkeley, (2002). Household's stoves: energy, health, and global warming (http://www.giss.nasa.gov/meetings/pollution2002/present/3 edwards).

European Commission. (2010). Joint Research Centre - Institute for Environment and Sustainability: International Reference Life Cycle Data System (ILCD) HandbookGeneral guide for Life Cycle Assessment—Detailed guidance. EUR 24708 EN. Luxembourg. Publications Office of the European Union. 
Flesch TK, Desjardins RL, Worth D., (2011). Fugitive methane emissions from an agricultural biodigester. Biomass and Bioenergy 2011; 35:3927-35.

Fulford D.J. (2015). Small-scale Rural Biogas Programmes: A handbook, Practical Action

Gautam, R., Baral, S., Herat, S., (2009). Biogas as a sustainable energy source in Nepal: present status and future challenges. Renewable and Sustainable Energy Review, 13, $248-252$.

Global Alliance for Clean Cookstoves. (2011). Igniting Change: A Strategy for Universal Adoption of Clean Cookstoves and Fuels. Accessed at: http://www.euei.net/sites/euei.net/files/Igniting-Change- 2011-2-MB-low-res.pdf.

Goedkoop M., M. Oele, J. Leijting, T. Ponsioen, and M. Ellen, (2016). Introduction to LCA With SimaPro

Gofran, M. A., (2009). Biogas Projukti (Biogas Technology - Translated by author), Bangladesh Biogas Development Foundation ISBN 984-32-1781-5.

Gold Standard (2014). SKG SANGHA BIODIGESTER PoA GOLD STANDARD PASSPORT GS Number: 1128

Grameen Shakti, (2005). A report on Biogas Plant Bangladesh, Grameen Shakti website, http://www.gshakti.org/index.php?option=com_content\&view=article\&id=61\&Itemid ter Heegde, F. (2008). Domestic Biogas Projects and Carbon Revenue: A strategy towards sustainability?, SNV Netherlands Development Organisation. The Hague, Netherlands Hijazi, O; Munro, S; Zerhusen, B and Effenberger, M. (2016). Review of life cycle assessment for biogas production in Europe. Renewable and Sustainable Energy Reviews. Vol. 54, 1291-1300.

Huque Saiful, (2017). Carbon Footprint: Process and Methodology of Carbon Footprint Measurement for Banks and Financial Institutions. Carbon footprint conference organised by Dhaka University and Future Carbon Ltd UK; Dhaka, Bangladesh. 
IDCOL, (2008). IDCOL and SNV Biogas plant construction manual for "National Domestic Biogas and Manure Program.

Islam, M.S., (2006). Use of Bioslurry as Organic Fertilizer in Bangladesh Agriculture. Prepared for Presentation at the International Workshop on the Use of Bioslurry Domestic Biogas Programmes.

ISO, (2006). Environmental management - life cycle assessment - requirements and guidelines, International Standards Organization, EN ISO 14044

Jayasundara, S., Wagner-Riddle, C., Dias G., Kariyapperuma, K.A., (2014) Energy and greenhouse gas intensity of corn (Zea mays L.) production in Ontario: A regional assessment, Canadian Journal of Soil Science, 94(1): 77-95

Joep P. M., (2011). The right environment limited company. http://www. The right environment.net /Downloads/Life_Cycle_Assessment_Leaflet_1.01.PDF

Kalra M. S. and J. S. Panwar, (2003). Anaerobic digestion of rice crop residues, Indian Agricultural Research Institute, New Delhi 110012, India, Agricultural Wastes, 17(4), 263-269.

Khandelwal, K.C. and Gupta, V.K. (2009) Popular Summary of the Test Reports on Biogas Stoves and Lamps prepared by testing institutes in China, India and the Netherlands, SNV Netherlands Development Organisation

Lafarge Bangladesh, (2007). Lafarge Islam Cement Limited, Summary Environmental Impact Assessment.

Li Z, Tang R, Xia C, Luo H, Zhong H ; (2005). Towards green rural energy in Yunnan, China; Renewable Energy, 30, 99-108.

Mirza U.K, Ahmad N, Majeed T; (2008). An overview of biomass energy utilization in Pakistan; Renewable and Sustainable Energy Review, 12, 1988-1996.

Nguyen, T. \& Gheewala S., (2008). Life cycle assessment of fuel ethanol from cane molasses 
in Thailand, The International Journal of Life Cycle Assessment, vol.13, no. 4, pp. 301311. 2008

PAS 2050 (2011) Specification for the assessment of the life cycle greenhouse gas emissions of goods and services; BSI, UK

Rahman KM, Woodard R, Manzanares E, Harder MK., (2014). Anassessment of anaerobic digestion capacity in Bangladesh. Renewable and Sustainable Energy Review; 32:762-9. http://dx.doi.org/10.1016/j.rser.2014.01.026.

Rahman K. M., (2012). Determination of the Potential Energy Contribution and Green House Gas Mitigation of Small and Medium Anaerobic Digester Systems in Bangladesh, University of Brighton, [Ph.D. thesis]

Sasse L; (1988). Biogas Plants; A Publication of the Deutsches Zentrum für Entwicklungstechnologien GATE in: Deutsche Gesellschaft für Technische Zusammenarbeit (GTZ) GmbH.

Sepp, S., Volkmer H. (2014) Multiple-Household Fuel Use: a balanced choice between firewood, charcoal and LPG; GIZ

SimaPro, (2013). Putting the metrics behind sustainability SimaPro Brochure, https://www.pre-sustainability.com/download/Corporate-Brochure-International.pdf

Smith K. R., J. Rogers, and S. C. Cowlin, (2002). Household Fuels and Ill-Health in Developing Countries: What improvements can be brought by LP Gas? World LP Gas Association and Practical Action.

SNV/IDCOL, (2005). Technical Study of Biogas Plants Constructed in Bangladesh. (Draft report).

SNV - Dutch development agency, (2011). Ashden technology: Biogas, Link: https://www.ashden.org/biogas

Tao L. and J. Han, (2015). Waste-To-Energy Techno-Economic Analysis and Life-Cycle 
Analysis. US DOE Bioenergy Technologies Office (BETO) 2015 Project Peer Review.

Thien Thu, C. T., P. H. Cuong, L. T. Hang, N. V. Chao, L. X. Anh, N. X. Trach, and S. G. Sommer, (2012). Manure management practices on biogas and non-biogas pig farms in developing countries - using livestock farms in Vietnam as an example. Journal of Cleaner Production. 27:64-71.

van Nes Wim J., Willem Boers and Khurseed-Ul-Islam, (2005). Feasibility of a national programme on domestic biogas in Bangladesh. Final Report. Netherlands Development Organization, the Netherlands.

Vu, T., Vu, D., Jensen, L., Sommer, S., Bruun, S., (2015). Life cycle assessment of biogas production in small-scale household digesters in Vietnam. Asian-Australasian Journal of Animal Sciences 28 (5), 716-729.

Wilson, D.C., Adebisi O. A, Kaine C and Christopher R. C, (2009). Building recycling rates through the informal sector. Waste Management, 29, 629-635

World Health Organisation, Report, (2015). Indoor air pollution, health and the burden of disease.

Zbicinski I., Stanenuiter J., Kozlowska B. and H. ven de Coevering, (2006). Product Design and Life Cycle Assessment. Book 3 in a series on Environmental Management, The Baltic University Press, ISBN: 975526-2-3 